\title{
Das formas de controle e disciplinarização à resistência operária no cotidiano fabril: o trabalho na indústria farmacêutica*
}

\author{
SÔNIA Aparecida Lôbo \\ Doutora em Sociologia \\ Professora da UEG e CEFET-GO \\ soaplobo@hotmail.com
}

\begin{abstract}
Resumo
A indústria farmacêutica tem passado por importantes transformações tecnológicas e organizacionais desde a década de 1990. Nesse contexto um elemento tem se destacado como específico e fundamental nos processos de trabalho dessa indústria: o controle da produção por meio da regulamentação sanitária. O controle sanitário na indústria farmacêutica passou a integrar as formas de organização e gestão da força de trabalho sendo, em vários aspectos seu elemento estruturante: das rotinas, dos hábitos, da busca da qualidade na produção, do controle e disciplinarização dos trabalhadores e da conquista de sua adesão aos processos produtivos pelo discurso da produção da saúde por meio da qualidade do medicamento. Atua assim, como elemento constitutivo dos processos de trabalho e da geração de valor. Paralelamente, os trabalhadores dessa indústria que se defrontam com as rotinas restritivas inerentes à produção de medicamentos, tecem interpretações e mesclam aceitações e negações diante de exigências de produção e controle esboçando resistências, por vezes sutis, mas cotidianas às mesmas.
\end{abstract}

Palavras-chave: indústria farmacêutica; controle sanitário; resistência.

\section{Introdução}

A atividade alienada não produz só a consciência alienada, mas também a consciência de ser alienado (Mészáros, 2006, p. 166).

A s formas de alienação inerentes ao sistema do capital se revelam, 1 no espaço fabril, na dominação que os capitalistas detêm das condições de trabalho, que se tornaram autônomas frente aos operários (Marx, 1996, p. 55). O processo de construção dessa dominação e alienação traz simultaneamente a possibilidade de aceitação dos processos alienantes, pela prevalência hegemônica do capital e de sua negação, pelas contradições que se dão nas relações concretas entre capital e trabalho.

São essas contradições engendradas na produção e na sociedade que colocam em questão os próprios limites de reprodução social, permitindo que os trabalhadores teçam uma consciência diferenciada daquela imposta pelo capital.

* Esse artigo deriva de pesquisa realizada entre os anos de 2004 e 2005 em duas indústrias farmacêuticas pertencentes ao pólo existente no eixo Goiânia-Anápolis. Foi apresentado originalmente como capítulo de tese, defendida em 2007, no Programa de Pós-Graduação em Sociologia Política da Universidade Federal de Santa Catarina, sob a orientação da Profa. Dra. Bernardete W. Aued. 
Nesse artigo, o cotidiano fabril da indústria de medicamentos é acessado por meio dos depoimentos dos trabalhadores e formas de aceitação e negação aos processos de produção são delineadas. Paralelamente procuramos compreender como as rígidas rotinas relativas aos processos de trabalho se relacionam com o conceito de qualidade desenvolvido pela legislação sanitária vigente, passando a integrar as formas de organização e gestão da força de trabalho, sendo estruturante dessas rotinas, dos hábitos, da busca de disciplinarização dos trabalhadores e da conquista de sua adesão aos processos produtivos mediante o discurso da produção da saúde por meio da qualidade dos medicamentos.

\section{Controle sanitário e produção de medicamentos}

Ao adentrar na indústria farmacêutica o trabalhador depara-se com uma rotina que é marcada, em primeiro lugar, pelos processos de higiene e cuidados com o seu corpo; depois, com a assepsia do seu local de trabalho e das máquinas com as quais irá lidar. Esses cuidados são orientados por uma série de restrições, proibições e normas a serem seguidas. Estas vão desde a higienização correta das mãos, do uso apropriado dos equipamentos de proteção até a restrição ao seu deslocamento dentro do ambiente fabril. Toda essa rotina é pautada pelas normatizações sanitárias que orientam o cotidiano do trabalho e da produção na indústria farmacêutica.

Essa indústria em seu conjunto passou por importantes transformações tecnológicas e organizacionais desde a década de 1990. No entanto, tão importante quanto essas mudanças foram os avanços das exigências de controle sanitário. Em 1999 foi criada a Agência Nacional de Vigilância Sanitária (Anvisa), investida de maior poder de fiscalização. Sua criação se inseria dentro de uma proposta de modernização da vigilância sanitária no Brasi $1^{1}$ e ocorreu dentro do âmbito da formação do Mercosul e da necessidade de uma regulamentação e fiscalização claras quanto às questões sanitárias.

Nesse contexto, a questão da qualidade aparecerá como central nas novas normatizações. A regulamentação da Lei de Genéricos pela Resolução 391/99 da Anvisa, por exemplo, avança no sentido de aprofundar esse aspecto. No passado a qualidade era pensada apenas do ponto de vista do princípio ativo dos medicamentos, sua correta identificação e pureza. A composição química era vista como uma garantia da qualidade desse medicamento. Posteriormente a técnica avançou para a equivalência farmacêutica dos medicamentos. Com a política de genéricos e a discussão sobre a bioequivalên$\mathrm{cia}^{2}$, outros aspectos físico-químicos, alguns aspectos da tecnologia de produção e da farmacologia passam a fazer parte da qualidade (Gemal, 2004, p. 178).

No que diz respeito à produção, a Anvisa publicou em agosto de 2003 a RDC n. 210, que regulamenta as Boas Práticas de Fabricação (BPFs). A resolução enfoca e regulamenta os procedimentos a serem seguidos para a produção de medicamentos, tendo como eixo a busca da qualidade na produção.

Nesse sentido a resolução estabelece que todos os procedimentos devem ser realizados por meio do Procedimento Operacional Padrão (POP), que orienta e controla todas as etapas da produção: do armazenamento ao produto final. Destaca, ainda, a importância dos processos de sanitização e de higiene a serem observados. Essas atividades abrangem não só as instalações, equipamentos, materiais de produção, mas também os trabalhadores. Determina que todas as responsabilidades individuais devem estar estabelecidas em procedimentos escritos e claramente compreendidos por todos os envolvidos. Preconiza ainda que todos os trabalhadores devem conhecer os princípios da Boas Práticas de Fabricação (BPFs), o conceito de Garantia da Qualidade e receber treinamento, incluindo instruções de higiene e de suas atribuições pessoais.

No cumprimento dessas normas temos a definição de uma série de elementos relativos aos processos de trabalho e ao cotidiano dos trabalhadores dentro da indústria farmacêutica, como veremos.

\section{Do controle ao autocontrole: o corpo do trabalhador}

O controle de qualidade incide sobre o processo de trabalho e formação dos trabalhadores, fazendo parte dos conhecimentos que eles têm que adquirir e comportamentos que têm que desenvolver no trabalho, levando a um envolvimento direto de sua subjetivida-

1 Segundo Gemal (2004, p. 175): "O governo federal moderniza o sistema de vigilância que já existia - que uns consideravam cartorial, ineficaz, ineficiente, corrupto, enfim, todo uma série de adjetivos não muito agradáveis, mas que a qualificavam no passado. A criação da Anvisa [...] além do processo de modernização do ponto de vista administrativo, modernização do ponto de vista técnico e financeiro, na fonte de receita, da fórmula com que poderia trabalhar com a chamada independência financeira. São criadas novas taxas, são criados novos mecanismos para tornar a vigilância sanitária auto-suficiente."

2 Para que um medicamento seja considerado genérico é necessário que ele seja bioequivalente, ou seja, que administrado na mesma dose molar, nas mesmas condições experimentais, não apresente diferenças estatisticamente significativas com relação à velocidade e à extensão de absorção de um princípio ativo. 
de com o processo de produção de medicamento. Em um primeiro momento esse controle e disciplinarização incidem sobre o próprio corpo do trabalhador.

Durante a produção, seguir o procedimento de trabalho correto no que diz respeito ao próprio corpo resulta em despojá-lo e ocultá-lo: proíbe-se o uso de maquiagem, barba, bigode e adornos. As unhas devem ser curtas e limpas (sem o uso de esmaltes), os cabelos devem estar presos e o uso da touca é obrigatório. O corpo é coberto por um uniforme que pode ser mais ou menos extensivo, dependendo da área em que se trabalha.

Essas restrições são assimiladas no cotidiano da maioria dos trabalhadores. No entanto, o relato de resistências às mesmas não são incomuns. Homens cuja família tradicionalmente usa barba têm resistência em tirá-la. O mesmo ocorre com o uso da aliança, que muitos querem manter. Mulheres insistem no uso da maquiagem, principalmente o batom. Quanto ao uso do uniforme, o depoimento de Antônio ${ }^{3}$ é exemplar:

No início as pessoas conversavam entre si, mas elas não sabiam quem era quem. As pessoas saíam para o almoço e não se reconheciam. Com o uniforme fica todo mundo fechado. Daí então você começa a reconhecer pelo olho. Existem alguns setores, como o setor de anti-retrovirais e de antibióticos, em que a proteção tem que ser maior. Então, além do gorro, do jaleco, de luvas, da calça e da máscara de pano, há uma máscara de carbono e uma espécie de capuz que vem até a nuca e que possui uma corda para amarrar no pescoço. Ela fecha todinha. Nesses setores você só vê o olho. E dependendo do setor tem que usar óculos de proteção, por causa do pó. Pois há uma dispersão muito grande, principalmente nos antibióticos. Além disso, o problema maior desse setor é o mau cheiro que fica no corpo.

O que mais incomoda no uso do uniforme é o anonimato imposto. O uniforme, associado aos equipamentos de proteção industrial, promove o ocultamento e padronização dos corpos, dificultando o reconhecimento. O seu uso, associado à proibição de qualquer adorno ou maquiagem que pudessem vir a distinguir um trabalhador do outro, torna a todos iguais, indistintos dentro do espaço de trabalho. Só o convívio constante é capaz de quebrar o anonimato e o distanciamento, o que é feito pelo olhar. No cumprimento das normas de produção, a uniformização nega o indivíduo.

Nas sociedades contemporâneas e industrializadas, a incorporação do trabalhador coletivo ao espaço fabril conviveu com o processo de crescente individualização da sociedade. Porém, como destaca Marx (1971, p. 91), a conformação da individualidade sob o capitalismo está intrinsecamente ligada ao desenvolvimento de uma indiferença em seu seio. Esta se caracteriza pelo fato de que as diferenças de casta, estamento e sangue e todas as formas de dependência pessoal desaparecem e passam a prevalecer as relações antagônicas. Nesse sentido, há uma indiferenciação entre os sujeitos que só se distinguem pela posse ou não do capital e funda-se uma outra diferença baseada no mundo das coisas.

Elias (1994), discorrendo sobre o processo de crescente individualização social, aponta-o como uma característica essencial da sociedade contemporânea, na qual uma falsa dicotomia entre indivíduo e sociedade se tornou cada vez mais acentuada e o ser humano crescentemente se percebe como um ser à parte da sociedade, como uma cápsula individual. A prevalência desse processo de individualização tem levado a um duplo processo subjetivo: de um lado, a necessidade de se destacar como ser único, por meio da realização de atos ou de comportamentos que o distingam de alguma maneira do grupo a que pertence, criando uma biografia pessoal que difira das demais ${ }^{4}$. Por outro lado, por um crescente sentimento de solidão frente aos outros e à necessidade de ser aceito como igual. Essa duplicidade de sentimentos, aparentemente contraditórios, tem caracterizado a formação de uma personalidade contemporânea que resulta na necessidade de realizações pessoais, mas também em forte sofrimento psíquico quando essas não são alcançadas. Diante das escassas e altamente seletivas oportunidades, definidas conforme a classe a que se pertença, as possibilidades de fracasso são grandes para a maioria das pessoas.

Nesse contexto, o trabalho coletivo e abstrato, no espaço fabril, pode ser caracterizado como de afirmação e negação da individualidade capitalista. Afirmação porque representa o espaço privilegiado do desenvolvimento da indiferença tecida sob o capital. E negação porque não permite o desenvolvimento das capacidades individuais, cada vez mais valorizadas e vistas como qualidade requerida ao ser humano, como valor universal, a-histórico e eterno. As novas formas de gestão do trabalho tornaram-se, em alguma medida, críticas da negação da individualidade e têm buscado, no engajamento pessoal e subjetivo de cada trabalhador novas formas de adesão ao trabalho e de extração de mais-valia. Devemos destacar que nessas formas de gestão a valorização da individualidade não se faz mediante a superação da alienação ou do sujeito indiferente. Busca-se a afirmação do indivíduo capaz 
e empreendedor de si mesmo. Não a afirmação do ser emancipado.

$\mathrm{Na}$ indústria farmacêutica, os processos de produção massificados e serializados, negadores das capacidades individuais e criativas, articulam-se ao processo de ocultação e despojamento do corpo. Não reconhecer e não ser reconhecido pelos colegas significa, nesse espaço, não se afirmar como indivíduo particular, com personalidade e dotado de vontades e capacidades.

A ocultação e despojamento do corpo do trabalhador como parte do processo de produção termina por levar ao desejo de negação desse corpo como elemento necessário para o bom desempenho produtivo. Assim se coloca Pedro ${ }^{5}$, gerente de Laboratório, a respeito da questão:

Todo mundo já se acostumou a usar o padrão "feio". Eles acham feio, mas na realidade é comum. No treinamento eu digo que aqui não tem que ter ninguém bonito e nem chamar a atenção de ninguém. Por isso a gente tem como norma tirar todos os badulaques, os brincos e a maquiagem. Porque no laboratório nenhum homem tem que atrair uma mulher, nenhuma mulher tem que atrair um homem. Então tem que se desmunir dessas armas.

A negação do corpo e o controle da sexualidade do trabalhador presentes nas diferentes formas de gestão da força do trabalho, apontadas por Gramsci (1984) como características do fordismo, atingem seu paroxismo e são justificadas pela necessidade do controle sanitário. Os interesses da produtividade agradecem. Ter o trabalhador como pura força de trabalho, sem a interferência do seu intelecto, do seu corpo e das limitações e desejos inerentes ao mesmo, provocando interrupções indesejáveis no ritmo da produção, talvez seja um dos grandes sonhos do capital.

Ao ocultamento, despojamento e negação do corpo do trabalhador alia-se a necessidade de disciplinarização dos seus corpos e mentes. Esse problema se faz explícito em duas outras questões relativas ao controle dos trabalhadores: o uso dos Equipamentos de Proteção Industrial e a aceitação da não-mobilidade dentro do espaço fabril.

Entre as maiores resistências apresentadas pelos trabalhadores para o cumprimento das normas de produção encontra-se o uso dos equipamentos de proteção. O motivo apresentado é o desconforto que provoca. Robson ${ }^{6}$ relata assim as dificuldades com o uso de EPIs:

É complicado. Quem nunca usou fica ofegante. A máscara deixa sem respiração. Você vai conversar com a pessoa e ela tira a máscara. É ruim, é horrível isso. Porque se você vai conversar com outro tirando a máscara pensando que ele não te entende por causa dela, na verdade ele não está te entendendo porque está com protetor auricular. Então dá uma certa agonia. Mas é obrigatório e você acostuma. Nesse mundo a gente se acostuma com tudo. Mas tem pessoas que não conseguem se adaptar. Pessoas que dão trabalho para acostumar. Tem gente que coloca só a cordinha do protetor auricular perto da orelha para disfarçar. Você chega perto e vê que é chefe.

O processo de disciplinarização passa não só pela educação dos trabalhadores quanto à importância do uso dos equipamentos de segurança como também pela punição, por meio de advertências, para aqueles que não se adequam. Mesmo assim, relatos como o de Robson são comuns, como também as estratégias para burlar o seu uso. Entre os fatores apontados pelos gestores para essa resistência está a origem social da maioria. Isso se agrava entre os trabalhadores mais velhos ou que estão no laboratório há muitos anos e vieram de uma prática diferenciada quanto à produção de medicamentos. Nessa perspectiva, as práticas culturais e os hábitos dos trabalhadores que migraram do campo para a cidade e dos velhos entrariam em choque com a rotina asséptica existente dentro da indústria.

Para os trabalhadores, o boicote ao uso dos equipamentos de proteção representa a fuga de uma rotina incômoda que agride o corpo e interfere nos seus sentidos. Luiz ${ }^{7}$, bastante jovem e com pouco tempo de trabalho, assim se refere ao uso dos equipamentos e das práticas de higiene exigidas:

Eu era mais desleixado com barba e unha. Mas agora todo domingo faço a barba e a limpeza nas unhas, tudo tranqüilo. Eu assimilei como uma rotina. No começo eu esquecia. Deixava a barba. Quanto aos EPIs, no início incomodavam bastante. Quando a gente começou a usar as máscaras e o abafador de ouvido foi muito incômodo. Mas até pela nossa própria segurança é melhor assimilar. Foi proposto, tem que usar. Hoje em dia eu já faço questão.

Em que pese a trajetória do trabalhador, de origem rural ou urbana, jovem ou velho, com escolaridade alongada ou não, com pouco ou muito tempo de trabalho, a resistência ao uso dos EPIs e às normas de higiene parece ser comum a todos. $\mathrm{O}$ que se diferencia é o grau de controle que o próprio trabalhador se impõe.

O mesmo se repete no que diz respeito ao confinamento ao posto de trabalho. O fato de os trabalha- 
dores não poderem circular livremente nos diferentes espaços de produção e muito menos fora deles, em prédios destinados, por exemplo, à administração, foi apontado como motivo de isolamento entre os operários. A fixação no posto de trabalho, seja na esteira, na operação das máquinas ou na manipulação, é considerada como um dos piores aspectos da produção fabril. Luiz $^{8}$ diz que "No começo era bastante difícil. Parecia que você estava num ambiente que você não podia sair. Uma prisão mesmo. E na verdade não pode.”

Essas restrições terminam por ser assimiladas pelos trabalhadores como autocontrole e conduzem a uma alta disciplinarização, que os impede de se movimentar e de abandonar o posto de trabalho - impedimentos estes que se estendem até à satisfação de suas necessidades biológicas.

Elias (1994) aponta que um dos aspectos do processo de individualização social é caracterizado, justamente, pela intensificação das tensões entre os ditames e proibições sociais internalizados como autocontrole e os impulsos sociais reprimidos, que faz com o indivíduo veja-se internamente como uma pessoa e externamente como outro ser, moldado ao que se convencionou ser adequado como comportamento.

Esse processo, historicamente desenvolvido e caracterizado como avanço das noções de civilização, pode ser observado nas mais diferentes esferas da vida social. Ao mesmo tempo que as relações sociais se tornam mais complexas, levando a uma grande diferenciação das atividades humanas, rígidos padrões de comportamento desenvolvidos social e historicamente são impostos e internalizados, não se expressando simplesmente como controle, que se poderia dar pelo medo e pelo uso da repressão, mas como autocontrole. Nesse contexto, o não cumprimento dos padrões impostos é visto como um desvio social, algo a ser reprimido ou suprimido. Mesmo que os desejos individuais e mais íntimos caminhem em direção oposta às normas estabelecidas, o autocontrole faz com que o sujeito se adeqüe ao que é considerado socialmente aceitável.

Entre os trabalhadores da indústria farmacêutica, percebemos que o avanço do controle passa a ser autocontrole. As normas higiênicas e de comportamento impostas ao trabalhador, e que se manifestam como rotinas, são assimiladas a despeito do desconforto físico e psíquico. Quando o trabalhador atinge o nível do autocontrole, a adequação aos processos de trabalho se deu de maneira efetiva. Essa adequação é expressa pelos trabalhadores como algo ruim, mas necessário, ou como na expressão de Robson: "Nesse mundo a gente se acostuma com tudo". Aqueles que não conseguem o autocontrole devem ser constantemente controlados e vigiados externamente, no processo de produção.

\section{Rotinas: o processo de trabalho}

Nesse contexto, desenvolvem-se as rotinas relativas ao processo de produção de medicamentos, que são marcadas por um duplo processo de aceitação e negação por parte dos trabalhadores. $O$ trabalho na esteira, embalando medicamentos, é o que despende maior quantidade de força de trabalho. É o trabalho menos qualificado dentro do processo de produção, que exige menos treinamento e resulta em pior remuneração. Quase todos os trabalhadores iniciaram sua trajetória dentro da indústria por meio dessa função.

Um dos aspectos enfatizado é o seu caráter repetitivo. Antonio ${ }^{9}$ assim o descreve:

O trabalho em esteira é pior do que com a máquina. Você fica sentado, oito horas, uma situação incômoda. Curvado sobre uma esteira, vendo um medicamento passar, um sachê, um blister, um envelope, uma coisa assim. Só conferindo, embalando, revisando, parecendo uma peça de máquina. $\mathrm{O}$ trabalho parece uma coisa sem sentido. Não tem como você achar que o seu trabalho é importante. O trabalho na esteira é muito pesado fisicamente, a pessoa está fazendo a coisa de forma mecânica e não precisa usar nada do intelecto. Tanto que a exigência que eles fazem, para essa função, é o nível fundamental.

Para Joana ${ }^{10}$, além da repetição o maior incômodo do trabalho na esteira está no fato de o trabalhador se sentir descartável e ser facilmente substituível:

Uma das coisas que me incomodava quando eu estava na esteira é que você é totalmente substituível. Qualquer pessoa faz o que eu fazia. Então eu me sentia desvalorizada. O que me incomodava muito era isso: a gente ser completamente descartável. Se você não vier hoje, vem outro, fica no seu lugar e pronto. Porque é o que eu falo, depois que se entra para o Laboratório você só sabe contar até dez e até cinqüenta de dez em dez. É aquela coisa, você conta até dez e faz aqueles montinhos para o outro pegar. E o outro pega, conta de dez em dez e põe cinqüenta na caixinha. Eu penso que se a gente não trabalhar a mente, a gente acaba ficando meio bitolado, acaba ficando meio bobo, o raciocínio meio lento. Então, por isso, eu leio muito, para ver se eu não vou atrofiando.

Por meio desses depoimentos podemos dizer que o trabalho rotineiro, repetitivo, mas sem exigir o "uso do intelecto", como dizem Antônio e Joana, agrava-se pelo fato de que o trabalhador sabe que pode ser descartado e substituído a qualquer momento. 
Esse sentimento de ser descartável está referenciado em uma materialidade. É no dia-a-dia do desempenho da sua função, simples e repetitiva, que ele se enxerga como pertencente a um grupo de trabalhadores que apresenta alta taxa de rotatividade. Não só isso, mas como parte de um coletivo em que o seu trabalho individual não tem grande significação. $\mathrm{Na}$ segmentação do trabalho entre aqueles ligados diretamente à produção de medicamentos - chamados de trabalhadores de processo - e os trabalhadores da embalagem ou da limpeza, considerados secundários na produção tanto porque não determinam o seu ritmo quanto porque não oferecem risco maior para a contaminação do produto, consolida-se essa percepção de descartabilidade manifestada pelos trabalhadores.

Sair da esteira e ocupar um posto na manipulação, operação ou manutenção de máquinas é desejo expresso, visto como ascensão por implicar em melhor qualificação, remuneração e quebra na rotina. Entre os trabalhadores que lidam com a manipulação de medicamentos encontramos os mais orgulhosos com o trabalho desempenhado e que vêem grande importância no que fazem. Tomé ${ }^{11}$ assim descreve seu trabalho:

A parte de manipulação é muito complicada, porque a responsabilidade é grande. A atenção quando você entra para fazer a formulação de um produto é imensa. Então você fica tenso o tempo todo, concentrado o tempo todo. A dosagem certa para certa doença, outra dosagem para outro doente que tem uma doença que é pós-operatória, que é uma cicatrização. Se acontecer de você errar uma formulação e colocar uma quantidade maior de princípio ativo e acontecer também do controle de qualidade ter uma falha no equipamento, você solta um produto que vai acabar prejudicando pessoas. Você está trabalhando com cuidado de vida, então é uma responsabilidade que é incalculável para quem não vê como é que se faz. Já imaginou? Um dia lá fora falam assim: o produto manipulado pelo Laboratório matou tantas pessoas.

O outro lado do sentimento de orgulho e responsabilidade é o da tensão constante a que o trabalhador está exposto. Submetidos a um trabalho que é simultaneamente pesado e que exige um nível de atenção muito grande para seguir corretamente o procedimento para a mistura, o trabalhador costuma expressar uma rotina marcada pela necessidade de não errar.

Entre os operadores de máquinas mecânicas ou semi-automatizadas, outros aspectos são destacados: a repetição, o cansaço físico e a sonolência caracterizam a produção. Entre as tarefas do operador nessas máquinas é atribuída importância não só à capacidade de operá-las, considerada simples, mas também de conhecê-la e conseguir fazer a manutenção mínima da mesma. Até às vezes recorrendo à gambiarra, segundo expressão por eles usada. É um procedimento fora das normas, mas que existe em função de garantir as metas de produtividade.

Abastecer, programar a quantidade de produto a ser envasado, manter o local de trabalho higienizado e observar a máquina, eis a tarefa do operador, acrescida eventualmente da necessidade de pôr a máquina para funcionar mesmo quando apontar defeito.

Em setores da produção cujo processo é automatizado, outras questões são destacadas, entre elas a necessidade de atenção e o aumento da responsabilidade quanto ao controle de qualidade. No posto de trabalho de envase, dentro de uma área limpa destinada aos produtos injetáveis, Paulo ${ }^{12}$, que opera uma máquina automática, destaca que:

O principal é ter a área limpa. Você tem que tomar o maior cuidado porque a área é estéril. Você limpa a sala todo dia cedo e vê se está tudo ok. Confere tudo, se está descontaminado. Confere a máquina toda e vamos trabalhar! As ampolas vêm esterilizadas. Vêm dentro dos punhos. Elas entram na máquina, enchem as ampolas. Tem o maçarico que corta com fogo. Lá embaixo eu pego e vou montando as cargas. Qualquer coisa que eu fizer durante o processo tenho que anotar. Eu assino a ficha de liberação de envase, o início do lote, no caso. Eu sou responsável pelo envase. O controle de processo fica com outro pessoal, mas quanto à higiene da sala o responsável sou eu. O serviço é repetitivo, mas não dá tempo de descansar, exige atenção.

A ênfase no trabalho do operador recai sobre o controle sanitário. Como o operador não toca no produto nem nos frascos, sua tarefa é controlar o processo e garantir sua qualidade. $\mathrm{O}$ trabalho se intensifica e a atenção é continuamente exigida.

Associados a essas rotinas, encontram-se dois processos simultâneos e complementares de controle sobre a produção e os trabalhadores. Um diz respeito à garantia do cumprimento das metas de produtividade e outro à questão da qualidade sanitária do que está sendo produzido. No cotidiano, as duas formas de controle encontram-se presentes e se constituem em fator de pressão por parte dos gestores e em geração de estresse e cansaço entre os trabalhadores.

Manuel ${ }^{13}$, antigo trabalhador, que percorreu quase todos os postos de trabalho dentro da indústria, sendo operador durante longos anos, é taxativo: "O que mais se exige de um trabalhador é produzir". 
Com esse objetivo cria-se uma série de elementos de controle: vigilância pelas chefias, vigilância eletrônica por meio de cartão e de câmeras, metas rigidamente estabelecidas e com prazo para cumprimento. O controle para alcançar as metas de produção alia-se à pressão pela produção com qualidade sanitária. Em torno dessa necessidade vários elementos de controle são desenvolvidos pela indústria: treinamento, supervisão, fiscalização, ficha de controle de processo. Pe$\mathrm{dro}^{14}$, gerente de Laboratório, resume o trabalho do controle de qualidade dentro da indústria:

Se o colaborador não cumpre com o procedimento, isso é grave. É grave a ponto de se demitir. Até porque a responsabilidade final não é dele, é dos gestores. Então, se ele não cumpre um procedimento que o protege, a responsabilidade não é dele, é nossa. Tem que acioná-lo, entendeu?[...] O controle de qualidade se reveste de um caráter policialesco. O meu trabalho é visto assim. Tem esse caráter, pois tenho que duvidar o tempo todo das atividades desenvolvidas e ver se estão sendo realizadas corretamente. Essa vigilância e controle acabam sendo assumidos de forma clara.

Assim, em que pese o amplo grau de fiscalização existente dentro da indústria, exercida por funcionários especializados nessa função, a qualidade do produto é atribuída primeiramente ao operário e garantida pelos protocolos. Produzir bem significa produzir seguindo as regras de garantia da qualidade expressas pelas BPFs. E mais, produzir sem erros da primeira vez, sem que haja necessidade de reprocessar ou refugar um medicamento ${ }^{15}$.

Esse caráter policialesco do controle de qualidade gera desconforto entre os trabalhadores. Jean ${ }^{16}$ é categórico ao dizer:

\footnotetext{
Ah, é estressante. É muito estressante. Para você preparar um produto você tem que estar com a ficha de processo em mãos. Tem que ler aquela ficha todinha. Às vezes muda o processo. Dentro da indústria farmacêutica tem um setor de farmacotécnica que é onde se estuda o desenvolvimento do produto. Então, vira e mexe, eles estão fazendo a melhoria do produto, ou seja, encontrando o modo mais fácil de manipular. Daí você tem que ler a ficha, tem que preparar a máquina e tem que ser passo a passo. O que você fez tem que assinar. Então é muito cansativo e se sair errado o nome do cara está lá.
}

A associação entre a pressão para o cumprimento das metas de produção e a pressão para a garantia de qualidade termina sendo fator de estresse entre os trabalhadores. Ao trabalho repetitivo, monótono, sem criatividade se associa um sistema em que o não cumprimento das metas de produção ou das exigências da qualidade pode desencadear tanto a punição quanto a demissão do trabalhador. Nesse sentido, os trabalhadores realizam um esforço constante de adaptação e cumprimento dos processos.

\section{Produtores de medicamentos ou produtores de saúde?}

Permeando esse cotidiano, um elemento importante ligado a produção de medicamentos e que visa conformar os trabalhadores aos processos de trabalho dentro dessa indústria, ganhando sua adesão no terreno de sua subjetividade, é o discurso de que a sua produção está voltada prioritariamente para a saúde da população ${ }^{17}$. Discurso esse que se reflete nos depoimentos dos trabalhadores que, na sua quase totalidade, ressaltam a responsabilidade e o seu compromisso e da empresa com a melhoria ou manutenção da saúde da população.

A contraposição entre o trabalho árduo e a sua finalidade social é amplamente enfatizada e compreendida como motivo de orgulho, bem como de responsabilidade pessoal pela qualidade dos medicamentos produzidos. Robson ${ }^{18}$, operador de máquinas, assim se expressa a respeito:

Eu senti e sinto orgulho de estar trabalhando com medicamento, de contribuir para a saúde das pessoas. Eu sou uma pessoa que abraça as causas muito facilmente. Eu percebi nos cursos que a gente fez que estava produzindo medicamento para uma pessoa carente e que poderia ser meu familiar e eu mesmo, não é? Por que não? Eu poderia tomar remédio daqui. Eu fui abraçando essa causa com uma força muita grande.

Aqui uma dimensão subjetiva ganha peso: a do sentido que se atribui ao trabalho. Viemos demonstrando que a percepção dos trabalhadores sobre o seu cotidiano fabril é expressa como repetitiva, cansativa, estressante, monótona e que um grande número se percebe como plenamente substituível no interior da

14 Entrevista concedida à autora, Goiânia-GO, 07 de julho de 2005.

15 Segundo Humprey (1993, p. 240), no Just in Time, "para alcançar a qualidade é preciso produzir de imediato segundo um padrão correto, responsabilizando o operador por isso. O objetivo é expor os defeitos de qualidade e corrigí-los, em vez de esperar pela má qualidade."

16 Entrevista concedida à autora, Anápolis-GO, 16 de maio de 2005.

17 Nas empresas pesquisadas é comum ver referências à indústria como produtora de saúde. Essas referências aparecem em materiais promocionais, jornais internos e nos cursos de formação destinados aos trabalhadores.

18 Entrevista concedida à autora, Goiânia-GO, 23 de junho de 2005. 
fábrica. A concepção de que os trabalhadores da indústria farmacêutica são produtores de saúde atribui um sentido de utilidade ao seu fazer. Os sentimentos de inutilidade e de descartabilidade perante os processos de trabalho são contrapostos à utilidade, compreendida como destinação social de seu trabalho. Diante de um panorama marcado pelos baixos salários, alta carga horária a ser cumprida e ameaça constante de desemprego, o trabalho passa a ser (re)significado. Ganha uma dimensão humanitária. O outro, a saúde do outro, passa a dar respeitabilidade ao trabalho realizado. O trabalho que, sob o capitalismo, nega o ser porque alienado, passa aqui a ser (re)significado por meio de uma destinação maior.

No entanto, manifestações de descontentamento, como vistas anteriormente, continuam a permear o cotidiano de trabalho. Fortes contradições permitem entrever outro mundo. Questões como a saúde dos trabalhadores, as condições de trabalho a que são submetidos e finalmente os altos lucros auferidos pela indústria de medicamentos passam a compor o universo de contraposição ao discurso da destinação social da produção.

Não é necessário aprofundarmos a questão dos lucros incessantes auferidos pela indústria farmacêutica. Basta lembrarmos o volume de recursos despendidos em propaganda pelo setor ${ }^{19}$ e o crescente estímulo ao consumo irresponsável de medicamentos diretamente nas farmácias, que banaliza o seu uso, para compreendermos que a indústria não trata o medicamento a não ser como ele se apresenta na sua essência na sociedade capitalista: como mercadoria. Nesse aspecto, o invólucro de produto que serve à saúde presta-se apenas como mais um elemento de propaganda do setor.

Porém, as contradições da indústria com relação à questão da saúde apresentam-se com mais clareza aos trabalhadores no dia-a-dia. Antônio ${ }^{20}$, operador de máquinas, destaca a incongruência entre as exigências e restrições impostas pelo controle sanitário e o que ocorre na empresa:

Aqui entra a questão da exigência de como deve ser o procedimento de uso dos equipamentos. Porque tem algumas coisas que eles cobram muito, mas é hipócrita. Querem que se faça uma coisa certa de um lado, mas, de outro, fazem totalmente bagunçado. Então, nunca aquele processo vai seguir do modo certo como tem que ser. Às vezes, cai no uniforme um hipoclorito e já começa a causar furo na roupa, ou seja, já teve uma falha. Luva não é adequada. Não tem em quantidade suficiente. A vigilância sanitária proibiu algumas luvas, as cirúrgicas, mas a utilização maior era daque- las de borracha, mais grossas, elas eram autoclavadas. Isso não pode.

O distanciamento entre o que é cobrado dos trabalhadores e as condições de trabalho que lhes são oferecidas inviabiliza o próprio cumprimento das normas, coloca o trabalhador em risco e gera um ceticismo quanto à seriedade com que a empresa as cumpre.

Trabalhadores, especialmente os ligados à manipulação de medicamentos, alertam que os EPIs não são suficientes para barrar o contato com os produtos que estão sendo manipulados. Tomé, manipulador, ${ }^{21}$ relata que:

$\mathrm{Na}$ verdade o equipamento nos protege em parte. A gente não deixa de absorver o produto. $\mathrm{O}$ tecido do macacão deixa, às vezes, passar produto para a pele. A máscara também, conforme o movimento que você faz com o maxilar, você movimenta a máscara. Às vezes ela abre, cria uma fresta e entra um monte de pó. Acontece de você aspirar. Com o decorrer do tempo, eu tive problemas como falta de ar, de cansaço, por aspirar os produtos. Acontecia de eu manipular um produto muito tempo. Eu manipulava no caso o produto $\mathrm{X}$, que é um produto muito forte. E o certo era que a empresa, eu creio que tem um documento que foi passado para eles, fizesse um revezamento de pessoas que estão num setor para outro. Até para evitar a resistência ao produto. Era para ser feito de seis em seis meses. No caso, eu trabalharia seis meses na manipulação de antibióticos e seis meses na manipulação de outro produto, em outro setor. Eu fiz essa troca só uma vez em quase oito anos. Eu troquei e fiquei só três meses fora. Nunca mais fizeram esse revezamento de seis meses. Eles falavam que era feito, no papel era feito, mas na verdade não se fazia e isso era muito prejudicial. Eu cobrei várias vezes, mas eu não sei o porquê, eles não fizeram [...] Quem trabalha no setor de antibióticos deveria receber insalubridade. A informação que me deram foi o seguinte: quando a empresa fornece os equipamentos de segurança adequados ela não tem obrigação de pagar a insalubridade. Segundo eles, a proteção do equipamento seria cem por cento. O que não é verdade. Os que trabalham sentem.

A fala de Tomé aponta para questões relevantes: a responsabilização do trabalhador pela sua própria proteção mediante o uso dos EPIs; o não-reconhecimento pelas empresas de uma realidade relatada por vários trabalhadores - de que há contato com o

19 Calcula-se que 20\% do faturamento do setor é gasto em publicidade. Em 2004 a Indústria brasileira faturou em torno de 20 bilhões. Dados da Federação da Indústria Farmacêutica - Febrafarma. Revista da Indústria Farmacêutica, n. 4. jan/fev. 2004.

20 Entrevista concedida à autora, Goiânia-GO, 23 de junho de 2005.

21 Entrevista concedida à autora, Anápolis-GO, 26 de julho de 2005. 
princípio ativo dos produtos, especialmente no ato da manipulação - isentando-se da responsabilidade por doenças advindas desse contato; os sintomas relativos ao contato com esses medicamentos; o descumprimento de normas de segurança por parte da empresa, que não realiza o rodízio obrigatório entre os trabalhadores do setor.

Lopes (2000) aponta que, para grande parte dos engenheiros e técnicos de segurança, o problema da eliminação dos riscos existentes no trabalho fabril se resolve com a instalação de equipamentos de segurança. No entanto, pouco se faz a fim de afastar de fato os riscos do ambiente e de informar o uso correto dos equipamentos aos trabalhadores. No caso da indústria farmacêutica o caso se agrava, pois os depoimentos indicam a insuficiência do uso de tais equipamentos para a proteção correta dos trabalhadores.

Estudos sobre a saúde dos trabalhadores na indústria farmacêutica têm apontado questões recorrentes. Arizaleta (1995, p. 85) afirma que:

[...] la producción de medicamentos incorpora los riesgos por la exposición a múltiples agentes químico y/o farmacológicos utilizados em el proceso, los cuales se absorben através de piel y mucosas por la manipulación, asi como por la inhalación de partículas de polvo y gás.

A autora apresenta os problemas alérgicos, de respiração e fadiga como os mais comuns entre esses trabalhadores. Destaca ainda que, a par das doenças físicas relativas ao contato com produtos químicos e às questões ergonômicas, um número crescente de doenças relativas a transtornos psíquicos tem se apresentado. A tendência à mecanização e automação, que leva a uma extrema simplificação de tarefas, a repetição e a atividade carentes de conteúdo e interesse manifestam-se em transtornos mentais associados ao estresse e ao cansaço. Relatos dos trabalhadores desta pesquisa corroboram essa informação: as queixas de cansaço, estresse e mesmo depressão são constantes.

Aliado a essas doenças, o risco de acidentes de trabalho é grande. José, ${ }^{22}$ que foi operador e hoje trabalha na manutenção de máquinas, destaca a desqualificação do trabalhador para operar a máquina como motivo de acidentes recorrentes na empresa:

Eu vejo a necessidade de treinamento de pessoal. Mas, infelizmente, a necessidade da empresa faz colocar uma pessoa na produção e faz com que aconteçam acidentes como os que têm acontecido. Vai uma pontinha de um dedo, puxa um avental, puxa uma coisa. As máquinas são muito potentes e não dão tempo. Não ser uma pessoa qualificada para o trabalho é ruim. Tem que ter treinamento. Tem muitos que já saíram por causa disso. Não aceitam ficar porque não sabem. Então, como o salário também é pequeno, a pessoa se desinteressa e sai.

Lopes (2000, p 396) destaca que:

a maquinaria constitui a expressão mais concreta dos perigos existentes na fábrica. Da intimidade do trabalhador com seu equipamento depende, em grande parte, os sistemas de segurança instalados na produção.

$\mathrm{Na}$ investigação realizada, os trabalhadores acidentados geralmente são aqueles que são deslocados de sua função para substituir outros, às pressas, e sem uma qualificação adequada para o uso do maquinário. Nessa perspectiva, a relação entre a precarização das relações de trabalho, com alto turnover, a implementação de um sistema de rotatividade nos postos de trabalho e a falta de preparação dos trabalhadores no sentido da construção de um conhecimento relativo ao seu trabalho, podem ser apontados como fatores que intensificam os riscos dentro da indústria.

Nesse processo, a atribuição da responsabilidade ao trabalhador pelos riscos e a conseqüente desresponsabilização da empresa são fatos comuns. Lopes (2000, p. 399), estudando a questão da saúde dos trabalhadores dentro de uma indústria de freios, afirma que:

Interessa à empresa manter o debate em torno do ato inseguro, do uso do EPI, de assuntos ligados à saúde geral das pessoas (higiene, hipertensão arterial, diabetes, AIDS etc.) na tentativa de desviar o problema em direção aos limites das ações individuais e dos aspectos técnicos que envolvem a questão. Mascaramse, assim os efeitos próprios da produção capitalista sobre a saúde.

O fato da legislação atribuir ao uso do EPI a solução para o problema da contaminação química dentro das indústrias é ilustrativa desse fato. Daí decorre que o trabalhador se torna pessoalmente responsável pela manutenção da sua saúde por meio do uso correto do equipamento. Por outro lado, acidentes com o maquinário são atribuídos com freqüência à falha humana: desatenção e não cumprimento das regras de segurança. Ao individualizar o risco a indústria esconde as verdadeiras relações existentes no interior do espaço fabril, caracterizadas pelo autoritarismo na imposição das regras, normas de segurança e produção, jamais discutidos com os operários.

Essa contradição entre a construção de um ideal de produtores de saúde, como espaço de significação para o trabalho operário, e a dilapidação de sua saúde no processo de produção, pela subordinação do trabalho vivo ao trabalho morto, permeia de forma indelével as relações dentro da indústria farmacêutica. 


\section{Concluindo: controle sanitário, produção de valor e resistências no processo de produção de medicamentos}

Na indústria farmacêutica o controle sanitário condiciona os processos de trabalho em vários aspectos. A imposição do controle de qualidade apresenta-se como uma necessidade sanitária, de atendimento às rígidas especificações quanto à pureza e à eficácia de uma mercadoria que, em última instância, deve servir à garantia da saúde. Porém, se a questão sanitária é fundamental, incidindo sobre os processos de produção e comercialização dos medicamentos, sua regulamentação irá, também, compor o rol de medidas adotadas pelas empresas para garantir a qualidade de sua mercadoria em sentido mais amplo.

A garantia da qualidade é apropriada, assim primeiramente como discurso para distinção dos produtos na disputa por mercados, diferenciando-os dos produtos de seu concorrente. Essa característica é constantemente enfatizada pelos empresários por meio do departamento de marketing, especialmente nas indústrias que produzem medicamentos de referência ${ }^{23}$ e que reforçam a marca do produto em detrimento do conhecimento do princípio ativo neles presente e de sua ação sobre o organismo ${ }^{24}$.

Em segundo lugar, os princípios adotados para a garantia da qualidade na produção de medicamentos, que asseguram sua qualidade como valor de uso, termina por garantir a produção de valor.

Para Marx (1982, p.156), o desenvolvimento das forças produtivas do trabalho dependerá:

1. Das condições naturais do trabalho: fertilidade do solo, riqueza das jazidas minerais etc.; 2. Do aperfeiçoamento progressivo das forças sociais do trabalho por efeito da produção em grande escala, da concentração de capital, da combinação do trabalho, da divisão do trabalho, maquinaria, melhoria dos métodos, aplicação dos meios químicos e de outras forças naturais, redução do tempo e do espaço graças aos meios de comunicação e transporte e todos os demais pelos quais a ciência obriga as forças produtivas a servir ao trabalho e pelos quais desenvolve o caráter social ou cooperativo do trabalho.

Entendemos que o controle de qualidade insere-se dentro do processo de desenvolvimento das forças pro- dutivas do trabalho, representando um aperfeiçoamento dos métodos de trabalho que resulta em aumento da sua produtividade. Na produção de medicamentos, apesar da dissociação existente entre produção e garantia de qualidade indicada pela lei, que visa garantir que os últimos não estarão subordinados aos primeiros, é imperativo percebermos que as normas estabelecidas, em grande medida, favorecem o controle e a eficiência do ponto de vista estrito dos processos de produção, atingindo o objetivo primeiro das empresas produtoras de medicamentos: gerar mais capital.

Nesse sentido, em torno dessas práticas existe uma rotina em que produção e controle são inseparáveis. A vigilância sobre os operários quanto ao cumprimento das normas é rígida e se faz tanto pela análise do produto nas diferentes etapas quanto pela fiscalização e treinamento dos trabalhadores. Além do mais, todo o trabalho realizado pode ter o seu responsável identificado, uma vez que a assinatura nos protocolos de produção assegura visibilidade ímpar da atividade desenvolvida pelos trabalhadores. O controle sanitário constitui-se, assim, em forte elemento de disciplinarização da força de trabalho.

Um dos princípios atribuídos ao toyotismo, o da autonomação, passa também a ser cumprido. Segundo Wood (1993, p. 53), a autonomação refere-se ao controle autônomo dos defeitos. É a operacionalização do conceito de qualidade total, abandonando a centralização convencional do controle de qualidade limitada a uma inspeção especializada. Coriat (1993, p. 82) lembra ainda que, em sua efetivação, a autonomação inclui protocolos de responsabilidade pela qualidade dos produtos nos próprios postos de fabricação, o que é regra dentro da indústria farmacêutica.

A segregação dos espaços é outro resultado da busca da qualidade no que diz respeito ao seu aspecto sanitário. O operário é expressamente proibido de circular em áreas que não sejam a de seu trabalho para evitar que haja contaminação. Se for fazê-lo deve ter autorização formal. A proibição da circulação livre acaba reforçando e dando visibilidade a várias distinções entre os trabalhadores dentro das empresas, que refletem, também, sua situação ocupacional, profissional e hierárquica. As mais características talvez sejam as que se dão entre os trabalhadores da administração e os da fábrica, que normalmente não se conhecem ou não se relacionam; entre os trabalhadores dos laboratórios de análise e de desenvolvimento de produtos e os da produção; entre os que

23 São medicamentos inovadores.

24 A indústria farmacêutica de medicamentos de referência apresentou grande resistência à implantação dos medicamentos genéricos no Brasil. A introdução desses medicamentos no mercado significava tanto a redução de preços dos medicamentos quanto a perda de fatias do mercado, uma vez que o marketing da empresa fica prejudicado quando não é o nome da marca que é promovido, mas o nome do princípio ativo, significando a possibilidade de os consumidores migrarem para outros produtos. No cerne da crítica e da campanha dessas empresas contra a produção de genéricos está uma suposta perda de qualidade na produção dos medicamentos genéricos. 
trabalham em diferentes unidades produtivas; entre trabalhadores da manutenção e limpeza e os da produção. A segregação de espaços dentro das empresas reflete, outrossim, a própria segmentação existente entre trabalho manual e intelectual, direção e execução, agora respaldados pelo discurso sanitário. A dificuldade para transitar dentro da indústria acaba por confinar o trabalhador ao seu espaço de trabalho, onde pode ser mais controlado.

Finalmente, no espaço de produção, as contradições entre os interesses do capital e trabalho tornam-se o lócus da crítica dos trabalhadores: o trabalho repetitivo, frustrante do ponto de vista intelectual, a responsabilidade exigida, o estresse, constituem-se como algumas dessas contradições apontadas pelos trabalhadores.

\section{Referências}

ANDRADE, Carlos Drummond. Reunião. Rio de Janeiro: Livraria José Olimpio, 1974.

ARIZALETA, Cristina Montero. Proceso salud-enfermedad en las trabajadoras de uma industria farmacéutica. Dissertação (Mestrado) - Fundação Oswaldo Cruz. Escola Nacional de Saúde Pública, Rio de Janeiro, 1995.

BRASIL. Resolução RDC n. 210, de 04 de agosto de 2003. Ministério da Saúde. Agencia Nacional de Vigilância Sanitária. Brasília, DF, 2003.

CORIAT, Benjamin. Ohno e a Escola Japonesa de Gestão da Produção. Um ponto de vista de conjunto. In: HIRATA, Helena Sumiko (Org.). Sobre o modelo japonês: automatização, novas formas de organização e relações de trabalho. São Paulo: Editora da Universidade de São Paulo, 1993.

ELIAS, Norbert. A sociedade dos indivíduos. Rio de Janeiro: Jorge Zahar, 1994.

GEMAL, André L. Situação atual do sistema nacional de vigilância sanitária e a política de medicamentos genéricos no Brasil. In: BERMUDEZ, Jorge.A.Z. (Org.). Aceso a medicamentos: derecho fundamental, papel del Estado. Rio
A negligência com relação às normas sanitárias pelas próprias empresas, a insalubridade, as doenças relativas ao trabalho, os acidentes na produção promovem concomitantemente o questionamento, por parte dos trabalhadores, ao discurso da produção de saúde. Nesse contexto, a produção de medicamentos passa a se apresentar como hipotética construção da saúde da população e de desconstrução efetiva da saúde dos trabalhadores.

Os espaços de resistência têm se apresentado em ações cotidianas ligadas ao absenteísmo e turnover, persistentes nas empresas pesquisadas, ou ao descumprimento de normas impostas no processo de trabalho pequenas ações, geralmente individuais, que apontam para uma insatisfação perene quanto ao trabalho dentro da indústria e que apontam para a negação do trabalho alienado, destituído de sentido.

de Janeiro: ENESP, 2004.

GRAMSCI, Antônio. "Americanismo e Fordismo". In: Maquiavel, a política e o Estado Moderno. Rio de Janeiro: Civilização Brasileira, 1984.

HUMPREY, John. Adaptando o "Modelo Japonês" ao Brasil. In: HIRATA, Helena Sumiko (Org.). Sobre o modelo japonês. São Paulo: Editora da Universidade de São Paulo, 1993.

LOPES, José Carlos Cacau. A voz do dono e o dono da voz: trabalho, saúde e cidadania no cotidiano fabril. São Paulo: Hucitec, 2000.

MARX, Karl. Salário, preço e lucro. São Paulo: Ed. Abril Cultural, 1982. (Col. Os Economistas).

Capítulo VI inédito de O Capital. São Paulo:

Editora Moraes,1996.

MÉSZÁROS, István. A teoria da alienação em Marx. São Paulo: Boitempo Editorial, 2006.

WOOD, Stephen J. Toyotismo e ou Japonização. In: HIRATA, Helena Sumiko (Org.). Sobre o modelo japonês. São Paulo: Editora da Universidade de São Paulo, 1993. 


\title{
From the Forms of Control and Disciplinarization to Working Resistance in the Daily Production: Work in the Pharmaceutical Industry
}

\begin{abstract}
Pharmaceutical industry has gone through important technological and organizational changes since the 1990's. In this context, one element has been highlighted as specific and fundamental in the working processes of this industry: production control through sanitary regulations. Sanitary control in the pharmaceutical industry has integrated the organization forms and workforce management and it is, in many aspects, its structuring element of routines, habits and the search for quality in the production, control of workers and their adherence to the production processes of production through the discourse of health by means of medicine quality. Thus, it is a constituent element of work processes and generation of income. At the same time, workers of this industry, who have faced the restrictive routines, inherent to the production of medicines, make interpretations and mix acceptances and denials in consequence of production demands and control, showing resistance, sometimes subtle, but that occurs daily.
\end{abstract}

Key words: pharmaceutical industry; sanitary control; resistance.

Data de recebimento do artigo: 30-05-2008

Data de aprovação do artigo: 05-09-2008 